\title{
Somatic Embryogenesis in Hedychium bousigonianum
}

\author{
Hamidou F. Sakhanokho ${ }^{1}$ \\ U.S. Department of Agriculture, Agricultural Research Service, Thad Cochran \\ Southern Horticultural Laboratory, 810 Highway 26 W, Poplarville, MS 39470
}

Kanniah Rajasekaran

U.S. Department of Agriculture, Agricultural Research Service, 1100 Robert E. Lee Boulevard, Building 001 SRRC, New Orleans, LA 70124

\section{Rowena Y. Kelley \\ Mississippi State University, Department of Biochemistry and Molecular Biology, P.O. Box 9650, Mississippi State, MS 39762}

Additional index words. Hedychium bousigonianum, ethylene inhibitors, ornamental ginger, salicylic acid, silver nitrate, somatic embryogenesis

\begin{abstract}
An efficient primary somatic embryo (SE) and secondary somatic embryo (SSE) production system was developed for the ornamental ginger Hedychium bousigonianum Pierre ex Gagnepain. Addition of two ethylene inhibitors, salicylic acid (SA) and silver nitrate (AgNO3), to the culture media improved the system. Callus was initiated and proliferated on a medium containing Murashige and Skoog (MS) basal salts supplemented with $9.05 \mu M$ 2,4-dichlorophenoxyacetic acid and 4.6 $\mu$ M kinetin. Friable callus was transferred to a liquid medium containing MS basal salts, B5 vitamins, $0.6 \mu M$ thidiazuron, and 8.9 $\mu \mathrm{M}$ 6-benzylaminopurine to induce somatic embryogenesis. The effects of various concentrations of $\mathrm{SA}(0,25,50,75,100,125,150 \mu \mathrm{M})$ and $\operatorname{AgNO3}(0,10$, $20,30,40,50,60 \mu M)$ on callus growth, SE, and SSE development was further evaluated. The rate of callus growth decreased as the concentrations of SA or AgNO3 increased. AgNO3 and SA at all concentrations stimulated SE and SSE development better than the control although a decrease in embryo production was observed at higher concentrations of both SA and AgNO3. The best concentrations for SA were 75 and $100 \mu \mathrm{M}$, whereas for AgNO3, they were 30 to $50 \mu M$ for both SE and SSE production.
\end{abstract}

The genus Hedychium belongs to the Gingeberaceae family and consists of $\approx 80$ species. They are multipurpose plants (Gao et al., 2008; He, 2000), which are used as ornamentals and as raw material for manufacturing paper and perfumes. They are also used in ethnomedicine as a result of their antibacterial and antifungal activities. Several studies have shown that Hedychium species possess antifungal, antibacterial, and insecticidal properties (Bisht et al., 2006; Gopanraj et al., 2005; Medeiros et al., 2003). For transformation and other genetic improvement schemes, an efficient, rapid, and dependable regeneration system is required. Somatic embryogenesis is a regeneration scheme that is generally preferred over other in vitro developmental processes such as organogenesis because it offers more target cells (Ogita et al., 2002) and because somatic embryos (SEs) are believed to be of single cell origin, any regenerated transformed cell would give rise to a transformed plant without unwanted chimeric events often associated with transformed meristems. However, somatic embryogenesis is highly species- or genotype-dependent. Moreover, it is affected

Received for publication 30 Dec. 2008. Accepted for publication 12 Apr. 2009.

${ }^{1}$ To whom reprint requests should be addressed; e-mail hamidou.sakhanokho@ars.usda.gov. by various factors, including ethylene, a ubiquitous plant hormone with a variety of effects on plant growth and development, which has been reported to inhibit or promote in vitro plant growth and morphogenesis depending on the species (Al-Khayri and Al-Bahrany, 2001; Biddington, 1992; Kumar et al., 1998). Because of this, regulation of ethylene biosynthesis appears to be a promising approach for the development of more efficient tissue culture protocols in plant systems (Kumar et al., 2007). Incorporation of ethylene inhibitors in culture media has resulted in improved in vitro regeneration for several plant species (Adkins et al., 1993; AlKhayri and Al-Bahrany, 2001; Kumar et al., 1998, 2007). In particular, salicylic acid (SA) has been found to inhibit ethylene biosynthesis (Leslie and Romani, 1986). SA is a hormone-like substance that plays an important role in the regulation of plant growth and development, and it has received much attention in the last two decades because of its involvement in plant defense mechanisms under both biotic and abiotic stresses (Catinot et al., 2008; Métraux et al., 1990). Silver nitrate $\left(\mathrm{AgNO}_{3}\right)$, an inhibitor of ethylene signal transduction, has been shown to improve in vitro plant regeneration (Beyer, 1976; Chaudhuri and Kar, 2008; Kumar et al., 2007). Somatic embryogenesis has been achieved in some Hedychium species (Sakhanokho et al.,
2008), but there are no reports on somatic embryogenesis in Hedychium bousigonianum or on the effect of ethylene inhibitors on somatic embryogenesis response in any Hedychium species. Therefore, the objective of this study was to establish high-frequency plant production in Hedychium bousigonianum through somatic embryogenesis and assess the influence of the ethylene inhibitors, $\mathrm{AgNO}_{3}$ and SA, on SE and secondary somatic embryo (SSE) multiplication in this species.

\section{Materials and Methods}

Seed sterilization and in vitro germination. Seeds of Hedychium bousigonianum were collected from greenhouse-grown plants, scarified in $98 \%$ sulfuric acid $\left(\mathrm{H}_{2} \mathrm{SO}_{4}\right)$ (Fisher Scientific, Atlanta, GA) for $30 \mathrm{~min}$, rinsed three times for $5 \mathrm{~min}$ each time with running tap water to remove acid residues, and then surface-sterilized under a laminar flow hood by dipping them in $100 \%$ ethanol for $5 \mathrm{~min}$ with gentle shaking. Thereafter, seeds were rinsed with sterile distilled water and transferred to sterilized beakers containing $40 \%(\mathrm{v} / \mathrm{v})$ sodium hypochlorite solution and one drop of Tween ${ }^{\text {TM }} 20$ (Sigma, St. Louis, MO) and shaken for $20 \mathrm{~min}$ at 110 rpm. They were then rinsed three times with sterile distilled water and soaked overnight in sterile distilled water on a shaker at $110 \mathrm{rpm}$ at room temperature $\left(22^{\circ} \mathrm{C}\right)$. The next day, the seeds were rinsed again three to four times with distilled sterile water and transferred to $100 \mathrm{~mm} \times 15 \mathrm{~mm}$ (diameter $\times$ depth) petri dishes (Fisher Scientific) containing Murashige and Skoog (MS) (Murashige and Skoog, 1962) basal medium supplemented with $20 \mathrm{~g} \cdot \mathrm{L}^{-1}$ sucrose, $0.75 \mathrm{~g} \cdot \mathrm{L}^{-1} \mathrm{MgCl}_{2}$, and $2 \mathrm{~g} \cdot \mathrm{L}^{-1}$ Gelrite (Sigma).The $\mathrm{pH}$ of all media used was adjusted to 5.8 before autoclaving for $15 \mathrm{~min}$ at $121{ }^{\circ} \mathrm{C}$. The petri dishes were then placed in an incubator where the temperature was maintained constant at $28{ }^{\circ} \mathrm{C}$ with a photoperiod regime of 16-h light (100 $\left.\mu \mathrm{mol} \cdot \mathrm{m}^{-2} \cdot \mathrm{s}^{-1}\right)$ and $8 \mathrm{~h}$ dark. Most seed germinated within 35 to $40 \mathrm{~d}$.

Callus initiation and proliferation. Leaf explants were removed from 5- to 7-d-old in vitro germinated seedlings, cut into 3 - to 4-mm segments, and transferred to $100 \mathrm{~mm}$ $\times 20$-mm petri dishes containing the callus initiation and proliferation medium consisting of MS macronutrients and micronutrients (Murashige and Skoog, 1962) and $\mathrm{B}_{5}$ vitamins (Gamborg et al., 1968) supplemented with $9.05 \mu \mathrm{M}$ 2,4-dichlorophenoxyacetic acid and $4.6 \mu \mathrm{M}$ kinetin, $20 \mathrm{~g} \cdot \mathrm{L}^{-1}$ sucrose, $0.2 \mathrm{~g} \cdot \mathrm{L}^{-1}$ myo-inositol, $1 \mathrm{~g} \cdot \mathrm{L}^{-1}$ casein hydrolysate, $1 \mathrm{mg} \cdot \mathrm{L}^{-1}$ thiamine, $0.75 \mathrm{~g} \cdot \mathrm{L}^{-1}$ $\mathrm{MgCl}_{2}$, and $2 \mathrm{~g} \cdot \mathrm{L}^{-1}$ Gelrite (Sigma). The explants were incubated at $22{ }^{\circ} \mathrm{C}$ and $16-\mathrm{h}$ light $\left(100 \mu \mathrm{mol} \cdot \mathrm{m}^{-2} \cdot \mathrm{s}^{-1}\right) / 8-\mathrm{h}$ dark period. Once the cultures were transferred to $100 \mathrm{~mm} \times 20-\mathrm{mm}$ petri dishes, they were immediately sealed tightly with Parafilm ${ }^{\circledR}$ (Fisher Scientific) to prevent desiccation and microbial contamination. This step was repeated in subsequent cultures throughout the experiment. The drawback of such action, 
however, is the lack of adequate gas exchange leading to excessive ethylene accumulation, which may be detrimental to culture growth. After 4 weeks, induced callus in each petri dish was transferred to the same but freshly prepared callus proliferation medium. This step was performed three to four times every 4 weeks to select and proliferate friable callus.

In vitro liquid culture/primary embryo induction. Approximately $3 \mathrm{~g}$ of friable callus was transferred to $125-\mathrm{mL}$ flasks containing liquid media ( $70 \mathrm{~mL} /$ flask). The liquid media consisted of MS basal salts, B5 vitamins, $0.6 \mu \mathrm{M}$ thidiazuron (TDZ), and $8.9 \mu \mathrm{M}$ 6benzylaminopurine (BA), $20 \mathrm{~g} \cdot \mathrm{L}^{-1}$ sucrose, $0.2 \mathrm{~g} \cdot \mathrm{L}^{-1}$ myo-inositol, $1 \mathrm{~g} \cdot \mathrm{L}^{-1}$ casein hydrolysate, and $1 \mathrm{mg} \cdot \mathrm{L}^{-1}$ thiamine. The liquid media comprised of different treatments consisted of various SA $(0,25,50,75,100,125$, $150 \mu \mathrm{M})$ and $\mathrm{AgNO}_{3}(0,10,20,30,40,50,60$ $\mu \mathrm{M})$ concentrations (Sigma). The cultures were placed on an orbital shaker at $22{ }^{\circ} \mathrm{C}$ and agitated at $110 \mathrm{rpm}$ for 4 weeks.

Primary somatic embryo development. After the suspension culture step, the embryogenic calli $(\approx 0.5 \mathrm{~g}$ of embryogenic callus in each plate) were transferred to $100 \mathrm{~mm} \times$ 20-mm petri dishes containing SE development media consisting of different treatments of $\mathrm{SA}$ and $\mathrm{AgNO}_{3}$ concentrations. After 4 weeks, somatic embryogenesis response was recorded by counting the number of SEs per gram of callus developed in each plate. The SE development media were similar to the basic liquid media described previously, except that they also contained $0.75 \mathrm{~g} \cdot \mathrm{L}^{-1}$ $\mathrm{MgCl}_{2}$ and $2 \mathrm{~g} \cdot \mathrm{L}^{-1}$ of Gelrite.

Secondary embryo induction. In a second set of experiments, induction of SSEs was undertaken essentially following a procedure described by Kumar et al. (2007). Briefly, previously developed SEs (100 mg) were subjected to secondary somatic embryogenesis by transferring them to the same SA and $\mathrm{AgNO}_{3}$ treatments as described previously but containing half-strength MS macronutrients and micronutrients and half-strength $\mathrm{B}_{5}$ vitamins supplemented with $0.6 \mu \mathrm{M}$ TDZ, $8.9 \mu \mathrm{M}$ BA, $20 \mathrm{~g} \cdot \mathrm{L}^{-1}$ sucrose, $0.2 \mathrm{~g} \cdot \mathrm{L}^{-1}$ myo-inositol, 1 $\mathrm{g} \cdot \mathrm{L}^{-1}$ casein hydrolysate, $1 \mathrm{mg} \cdot \mathrm{L}^{-1}$ thiamine, $0.75 \mathrm{~g} \cdot \mathrm{L}^{-1} \mathrm{MgCl}_{2}$, and $2 \mathrm{~g} \cdot \mathrm{L}^{-1}$ Gelrite.

Plant regeneration and acclimatization. Plantlets were transferred from the petri dishes to $75-\mathrm{mL}(98.5 \mathrm{~mm} \times 59 \mathrm{~mm})$ culture vessels containing hormone-free MS basal medium supplemented with $20 \mathrm{~g} \cdot \mathrm{L}^{-1}$ sucrose, $0.75 \mathrm{~g} \cdot \mathrm{L}^{-1} \mathrm{MgCl}_{2}$, and $2 \mathrm{~g} \cdot \mathrm{L}^{-1}$ Gelrite. The plants were kept in a growth room at $22{ }^{\circ} \mathrm{C}$ with a photoperiod of $16 \mathrm{~h}$ light (100 $\mu \mathrm{mol} \cdot \mathrm{m}^{-2} \cdot \mathrm{s}^{-1}$ ) and $8 \mathrm{~h}$ dark. Most of the plants transferred to the vessels produced clumps of rooted multiple shoots. The clumps were divided into separate rooted plants, washed gently with tap water to remove residual callus or gelling agent, planted in premoistened Jiffy-7 peat pellets (Jiffy Products, Ltd., Shippagan, Canada), and covered with clear plastic bags. After $3 \mathrm{~d}$, holes were punched in the plastic bags to allow for gradual acclimatization of the plants before transplanting in the greenhouse after 4 to 6 weeks.
Experimental design and statistical anal$y$ sis. The experimental design was a completely randomized design comprised of different treatments of various SA $(0,25,50,75,100$, $125,150 \mu \mathrm{M})$ and $\mathrm{AgNO}_{3}(0,10,20,30,40,50$, $60 \mu \mathrm{M})$ concentrations. Each plate was weighed before the transfer of embryogenic callus and weighed again 4 weeks later to determine the relative growth rate of the embryogenic callus for each treatment. There were 20 replicates (plates) per treatment, and the experiment was repeated three times. Data collected included the relative growth rate calculated as a percentage of the initial embryogenic callus transferred in a plate and the number of SEs and SSEs per gram after $30 \mathrm{~d}$ in culture. The treatment means were calculated using SAS Institute (2003) software.

\section{Results and Discussion}

Effect of silver nitrate and salicylic acid on callus growth. Callus formation was observed within 2 to 3 weeks after the transfer of leaf explants to the callus initiation and proliferation medium. SEs (Fig. 1A) could be obtained in $\approx 30 \mathrm{~d}$ after transfer of embryogenic callus to the SE development media in all treatments, and plantlet formation could be observed within 2 weeks (Fig. 1A-B). Many plantlets developed roots within this period. Once transferred to culture vessels containing hormone-free MS basal medium, both rooted and nonrooted plantlets developed very quickly and were generally ready for acclimatization in premoistened Jiffy-7 pellets (Fig. 1C). After 4 weeks, callus growth taken after the primary SE development stage reached its maximum (362\% increase) after transfer of initiated callus to the control medium $\left(0 \mu \mathrm{M} \mathrm{AgNO}_{3}\right)$ before decreasing to only $281 \%$ in the medium containing the highest $\mathrm{AgNO}_{3}$ concentration $(60 \mu \mathrm{M})$ (Fig. 2A). There seems to be no consensus as to the role or effect of $\mathrm{AgNO}_{3}$ in callus growth because this effect appears

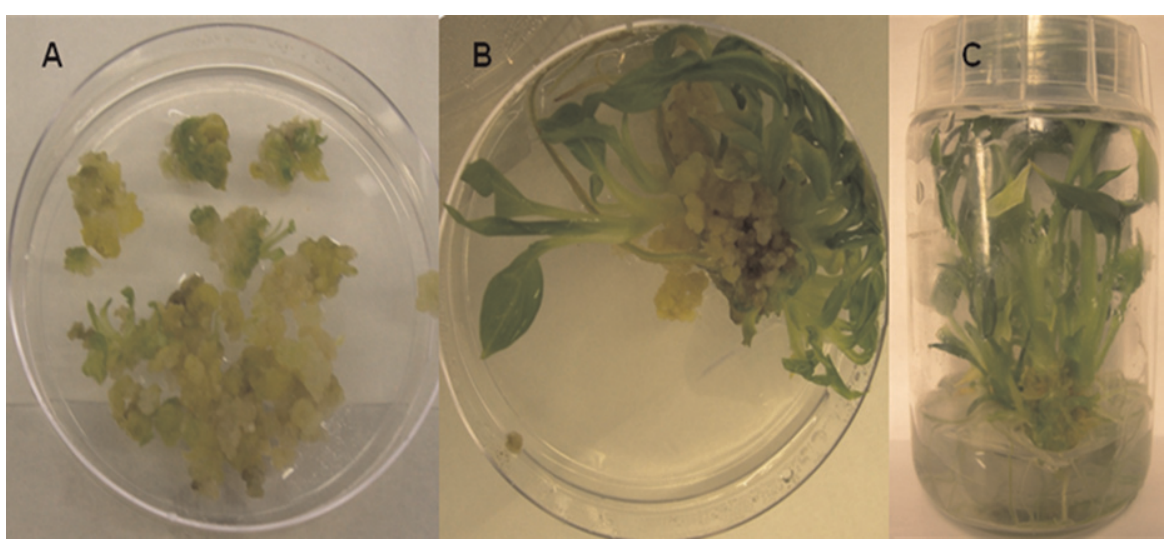

Fig. 1. Somatic embryogenesis and plant regeneration in Hedychium bousigonianum. (A) (75 $\mu$ M SA) Development of embryogenic callus and somatic embryos. The basic embryo development medium contained Murashige and Skoog macronutrients and micronutrients (Murashige and Skoog, 1962) and $\mathrm{B}_{5}$ vitamins (Gamborg et al., 1968) supplemented with $0.6 \mu \mathrm{M}$ thidiazuron, $8.9 \mu \mathrm{M}$ 6-benzylaminopurine, $20 \mathrm{~g} \cdot \mathrm{L}^{-1}$ sucrose, $0.2 \mathrm{~g} \cdot \mathrm{L}^{-1}$ myo-inositol, $1 \mathrm{~g} \cdot \mathrm{L}^{-1}$ casein hydrolysate, $1 \mathrm{mg} \cdot \mathrm{L}^{-1}$ thiamine, 0.75 $\mathrm{g} \cdot \mathrm{L}^{-1} \mathrm{MgCl}_{2}$, and $2 \mathrm{~g} \cdot \mathrm{L}^{-1}$ Gelrite. (B) $(30 \mu \mathrm{M}$ silver nitrate) Somatic embryo development and subsequent plantlet formation. (C) $\left(30 \mu \mathrm{M} \mathrm{AgNO}_{3}\right)$ Plantlets with well-formed roots ready for potting and acclimatization. to be species- or genotype-dependent. For example, $\mathrm{AgNO}_{3}$ had no effect on callus production of Zea mays L. (Vain et al., 1989), whereas it improved callus growth in et al. 2006). On the other hand, our result are in agreement with those of Tsao and Reed (2002) who reported that increased $\mathrm{AgNO}_{3}$ concentrations significantly reduced callus production in blackberry (Rubus spp.). A similar trend was observed with the addition of SA to the media because higher SA concentrations resulted in reduced callus growth rate, ranging from $358 \%$ for the control $(0 \mu \mathrm{M})$ to $305 \%$ for the highest SA concentration $(150 \mu \mathrm{M})$ (Fig. 2B). As concentration increased, the downward trend for callus growth was more consistent for $\mathrm{SA}$ than for $\mathrm{AgNO}_{3}$ (Fig. 2A-B). There was a zigzag pattern for callus growth for $\mathrm{AgNO}_{3}$ concentrations between $0 \mu \mathrm{M}$ (control) and $40 \mu \mathrm{M}$ (Fig. 2A). The reason for this is unclear, but the downward trend in callus growth became more straightforward steady for $\mathrm{AgNO}_{3}$ concentrations above $40 \mu \mathrm{M}$ Excessive callus proliferation is not generally conducive to somatic embryo initiation development. The enhanced somatic em$\mathrm{SA}$ and $\mathrm{AgNO}_{3}$ in the media and the subsequent reduced callus growth is not surprising.

Effect of silver nitrate and salicylic acid on primary somatic embryo formation. Addition of $\mathrm{AgNO}_{3}$ was beneficial to the formation of primary SEs of $H$. bousigonianum g. 3A). This positive effect of $\mathrm{AgNO}_{3}$ is 1976; Kumar et al., 2007). The highest SE production was reached at 40 and $50 \mu \mathrm{M}$ compared with $30 \mathrm{SEs} / \mathrm{g}$ for the control. The resulted in reduced SE production, but even at this concentration, production of SEs $(47 \pm 0.7$ versus $30 \pm 0.4)$ (Fig. $3 \mathrm{~A})$. The $\mathrm{AgNO}_{3}$ with 86 and $88 \mathrm{SEs} / \mathrm{g}$, respectively, remained higher than that of control SEs 


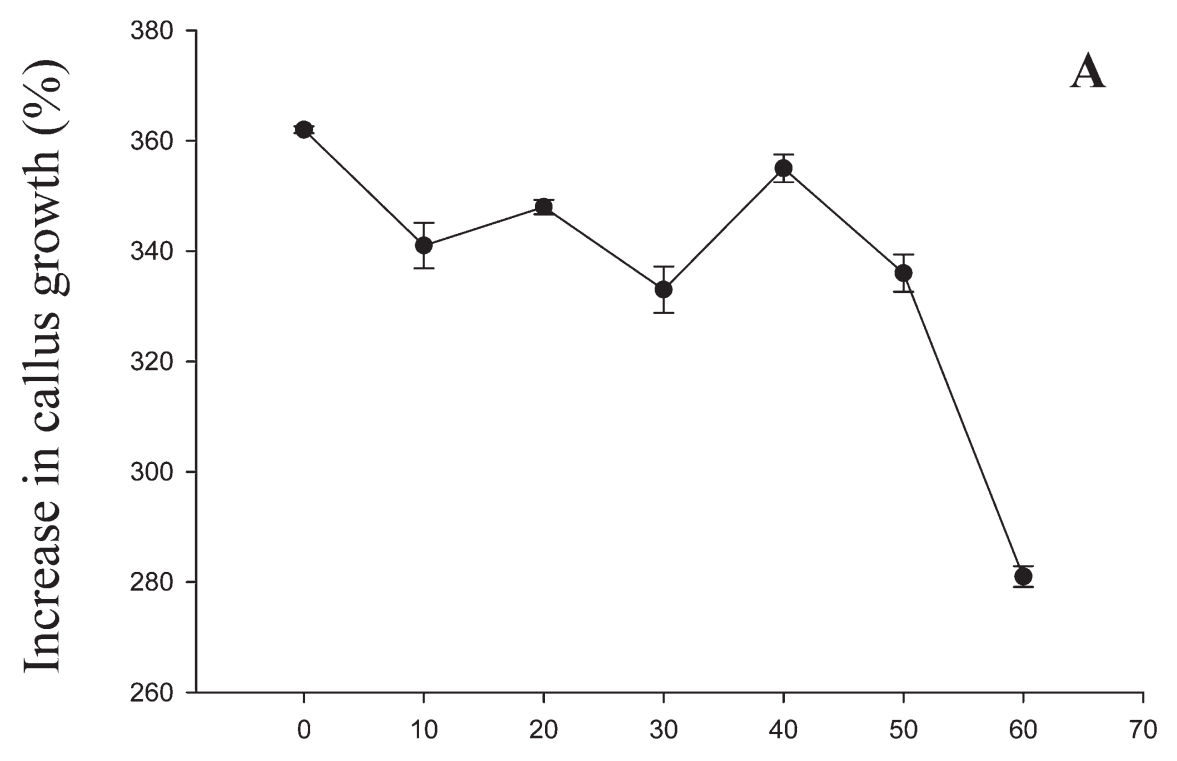

Silver nitrate concentration $(\mu \mathrm{M})$

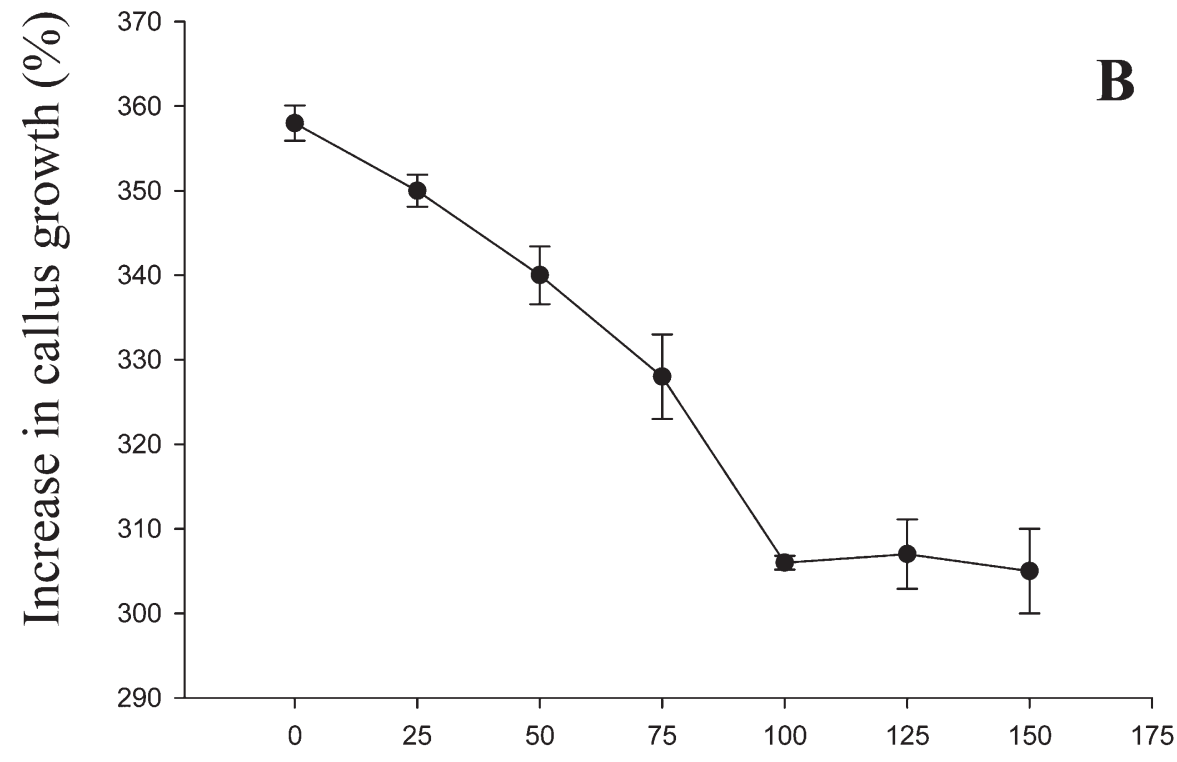

\section{Salicylic acid concentration $(\mu \mathrm{M})$}

Fig. 2. Effect of silver nitrate (A) and salicylic acid (B) on callus growth (percent increase from initial starting callus weight) in Hedychium bousigonianum. Each value represents mean \pm SE. Results are from 20 replicates, and the experiment was repeated three times.

addition of SA to the media also had a marked ameliorative effect on SE production (Fig. 3B). The best concentration was 100 $\mu \mathrm{M}$ SA, which produced $96 \pm 0.9 \mathrm{SEs} / \mathrm{g}$ of initial callus transferred. This represents a 3.8-fold improvement over the control ( $25 \pm$ $0.6 \mathrm{SEs} / \mathrm{g}$ ) (Fig. 3B). On the other hand, reduction in embryo production was observed at the $150 \mu \mathrm{M}$ SA level, suggesting an inhibitory effect of high SA concentrations on SE production. However, it is worth mentioning that even at this level, SE pro- any toxic effect or necrosis using higher concentrations of either SA or $\mathrm{AgNO}_{3}$ on somatic embryogenesis of $H$. bousigonianum despite a slight reduction in SE production at higher concentrations.

Effect of silver nitrate and salicylic acid on secondary somatic embryo. SSE production followed a similar pattern as that for SE induction, except that significantly more SSEs were produced than SEs with media containing both SA and $\mathrm{AgNO}_{3}$ (Fig. 3A-B). For $\mathrm{AgNO}_{3}$, the best media were those containing 30 and $40 \mu \mathrm{M}$ with averages of $212 \pm 1$ and $225 \pm 1.3 \mathrm{SSEs} / \mathrm{g}$, respectively (Fig. 3A). For SA, the 75 and $100 \mu \mathrm{M} \mathrm{SA}$ concentrations were the best performing media with $285 \pm 1.4$ and $283 \pm 1.7 \mathrm{SSEs} / \mathrm{g}$, respectively. For both SE and SSE production, the SA-containing media generally performed better than $\mathrm{AgNO}_{3}$-containing media (Fig. 3A-B). The current study using ethylene inhibitors demonstrated that secondary somatic embryogenesis is an efficient method for multiplication of SEs in H. bousigonianum, and plantlets could be obtained within 4 to 8 weeks. Such systems could be very useful for transformation studies or other in vitro genetic manipulations such as polyploidization. The system reported here could be particularly useful for mass propagation of this ornamental species. In addition, SEs may be encapsulated in various gelling agents to form artificial seeds that can be easily stored and transported long distances (Ghosh and Sen, 1994), a feature that can be very useful for a convenient and safe exchange of germplasm. SSEs result from the initiation and formation of new SEs from already formed primary SEs. Advantages of such a regeneration system include a high multiplication rate, independence of an explant source, reproducibility, and maintenance of embryogenicity for long periods of time through repeated cycles of secondary embryogenesis (Karami et al., 2008; Raemakers et al., 1995).

\section{Conclusion}

Higher concentrations of the ethylene inhibitors studied reduced callus growth, but there was a marked improvement in SE and SSE production after the addition of SA $(75$ and $100 \mu \mathrm{M})$ and $\mathrm{AgNO}_{3}(30$ to $50 \mu \mathrm{M})$ to the culture media. Overall, more SEs and SSEs were produced using the ethylene inhibitor SA than $\mathrm{AgNO}_{3}$. Neither SA nor $\mathrm{AgNO}_{3}$ is essential for somatic embryo initiation in $H$. bousgonianum. However, the results clearly indicate that significant increases in SE and, notably, SSE production occurred in the presence of $\mathrm{SA}$ and $\mathrm{AgNO}_{3}$ in culture media. In summary, we have established an efficient micropropagation system based on high-frequency SE production that can be useful not only for in vitro genetic manipulations, but also for industrial mass production of $H$. bousigonianum.

\section{Literature Cited}

stimulation of embryo production in carrot (Daucus carota L.) suspension cultures but that $250 \mu \mathrm{M}$ SA concentration had a toxic effect. In our study, we did not observe
Adkins, S.W., R. Kunanuvatchaidach, S.J. Gray, and A.L. Adkins. 1993. Effect of ethylene and 


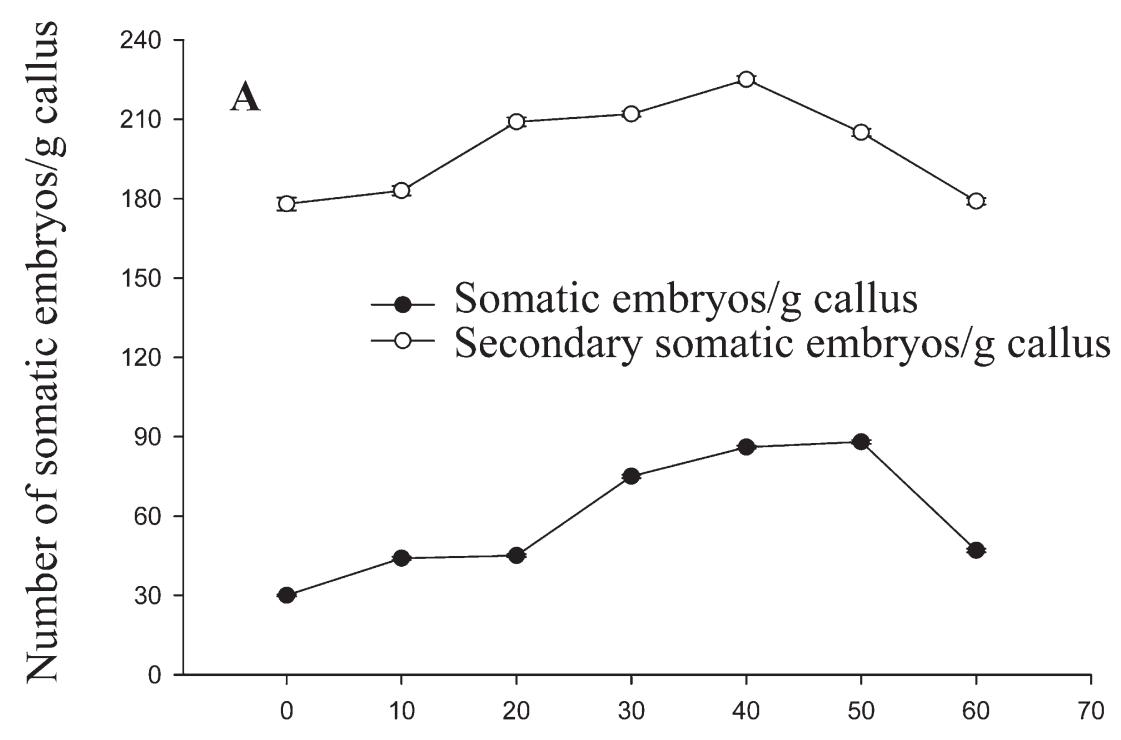

\section{Silver nitrate concentration $(\mu \mathrm{M})$}

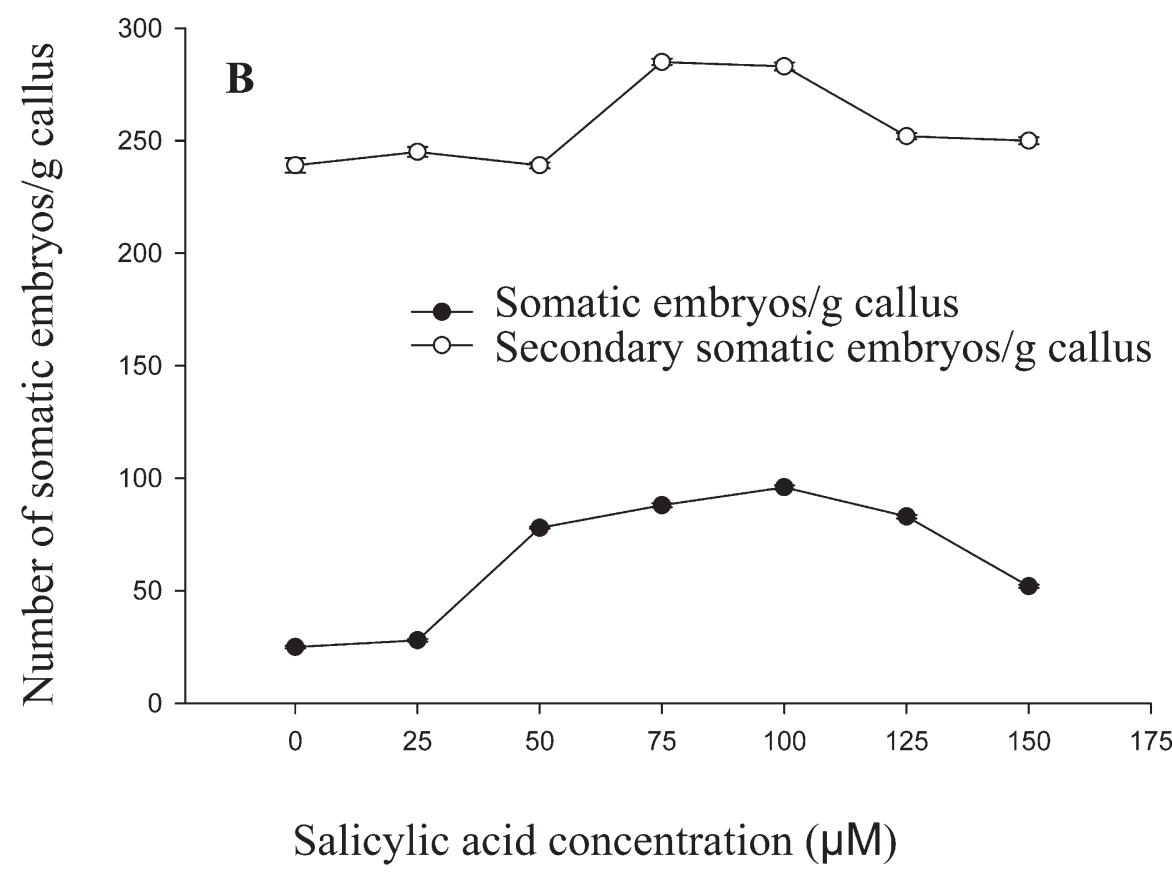

Fig. 3. Effect of silver nitrate (A) and salicylic acid (B) on somatic embryogenesis (number of embryos/g callus) and secondary embryo development (number of secondary embryos/g of primary SE) of Hedychium bousigonianum. Each value represents mean \pm SE. Results are from 20 replicates, and the experiment was repeated three times.

culture environment on rice callus proliferation. J. Expt. Bot. 44:1829-1835.

Al-Khayri, J.M. and A.M. Al-Bahrany. 2001 Silver nitrate and 2-isopentyladenine promote somatic embryogenesis in date palm (Phoenix dactylifera L.). Scientia Hort. 89:291-298.

Beyer, E.M., Jr. 1976. A potent inhibitor of ethylene action in plants. Plant Physiol. 58:268-271.

Biddington, N.L. 1992. The influence of ethylene in plant tissue culture. Plant Growth Regulat. 11:173-187.

Bisht, G.S., A.K. Awasthi, and T.N. Dhole. 2006. Antimicrobial activity of Hedychium spicatum. Fitoterapia 77:240-242.

Catinot, J., A. Buchala, E. Abou-Mansour, and J.P. Métraux. 2008. Salicylic acid production in response to biotic and abiotic stress depends
Gopanraj, G., M. Dan, S. Shiburaj, M.G. Sethuraman, and V. George. 2005. Chemical composition and antibacterial activity of the rhizome oil of Hedychium larsenii. Acta Pharm. 55:315-320.

He, E.Y. 2000. Study on Hedychium coronarium Koenig's edibility and its pharmacological experiments. Lishizhen. Medical Res. 11:1077-1078.

Karami, O., A. Deljou, and G.K. Kordestani. 2008. Secondary somatic embryogenesis of carnation (Dianthus caryophyllus L.). Plant Cell Tissue Organ Cult. 2:273-280.

Kumar, P.P., P. Lakshmanan, and T.A. Thorpe. 1998. Regulation of morphogenesis in plant tissue by ethylene. In Vitro Cell. Dev. Biol. Plant 34:94-103.

Kumar, V., A. Ramakrishna, and G.A. Ravishankar. 2007. Influence of different ethylene inhibitors on somatic embryogenesis and secondary embryogenesis from Coffea canephora $\mathrm{P}$ ex Fr. In Vitro Cell. Dev. Biol. Plant 43:602-607.

Leslie, C.A. and R.J. Romani. 1986. Salicylic acid: A new inhibitor of ethylene biosynthesis. Plant Cell Rpt. 5:144-146.

Luo, J.-P., S.-T. Jiang, and L.-J. Pan. 2001. Enhanced somatic embryogenesis by salicylic acid of Astragalus adsurgens Pall.: Relationship with $\mathrm{H}_{2} \mathrm{O}_{2}$ production and $\mathrm{H}_{2} \mathrm{O}_{2}$ - metabolizing enzyme activities. Plant Sci. 161:125-132.

Medeiros, J.R., L.B. Campos, S.C. Mendonça, L.B. Davin, and N.G. Lewis. 2003. Composition and antimicrobial activity of the essential oils from invasive species of the Azores, Hedychium gardnerianum and Pittosporum undulatum. Phytochemistry 64:561-565.

Métraux, J.P., H. Signer, J. Ryals, E. Ward, M. Wyss-Benz, J. Gaudin, K. Raschdorf, E. Schmid, W. Blum, and B. Inverardi. 1990. Increase in salicylic acid at the onset of systemic acquired resistance in cucumber. Science 250:1004-1006.

Murashige, T. and F. Skoog. 1962. A revised medium for rapid growth and bioassays with tobacco tissue culture. Physiol. Plant. 15:473-497.

Ogita, S., H. Uefuji, Y. Choi, T. Hatanaka, M. Ogawa, Y. Yamaguchi, N. Koizumi, and H. Sano. 2002. Genetic modification of coffee plants. J. Plant Biotechnol. 3:91-94.

Raemakers, C.J.J.M., E. Jacobsen, and R.G.F. Visser. 1995. Secondary somatic embryogenesis and applications in plant breeding. Euphytica 81:93-107.

Roustan, J.P., A. Latche, and J. Fallot. 1989. Effect of salicylic acid and acetylsalicylicon ethylene production and somatic embryogenesis in carrot (Daucus carota L.) cell suspensions. C. R. Acad. Sci. 308:395-399.

Sakhanokho, H.F., R.Y. Kelley, and K. Rajasekaran. 2008. First report of plant regeneration via somatic embryogenesis from shoot apexderived callus of Hedychium muluense R. M. Smith. J. Crop Imp. 21:191-200.

on isochorismate in Nicotiana benthamiana. FEBS Lett. 582:473-478.

Chaudhuri, A. and R.K. Kar. 2008. Effect of ethylene synthesis and perception inhibitors and ABA on seed germination of Vigna radiate. World J. of Agricultural Sci. 4:879-883.

Gamborg, O.L., R.A. Miller, and K. Ojima. 1968. Nutrient requirements of suspension cultures of soybean root cells. Exp. Cell Res. 50:151-158.

Gao, L., N. Liu, B. Huang, and X. Hu. 2008 Phylogenetic analysis and genetic mapping of Chinese Hedychium using SRAP markers. Sci. Hort. 117:369-377.

Ghosh, B. and S. Sen. 1994. Plant regeneration from alginate encapsulated somatic embryos of Asparagus cooperi Baker. Plant Cell Rpt. 12:381-385.
SAS Institute. 2003. SAS 9.1.3. SAS Institute, Inc., Cary, NC.

Tsao, C.W.V. and B.M. Reed. 2002. Gelling agents, silver nitrate, and sequestrene iron influence adventitious shoot and callus formation from Rubus leaves. In Vitro Cell. Dev. Biol. Plant 38:29-32.

Vain, P., H. Yean, and P. Flament. 1989. Enhancement of production and regeneration of embryogenic type II callus in Zea mays $\mathrm{L}$. by $\mathrm{AgNO}_{3}$. Plant Cell Tissue Organ Cult. 18:143-151.

Wu, L.M., Y.M. Wei, and Y.L. Zheng. 2006. Effects of silver nitrate on the tissue culture of immature wheat embryos. Russ. J. Plant Physiol. 53:530-596. 